difficult and expensive to introduce uniformity in the future, no matter how desirable proposed changes are. The advent of the trolley bus, which is much more mobile than a tramcar, will doubtless be a great help in the many years which will have to elapse before tramways become obsolete. Their popularity in Great Britain is due partly to the fact that, like electric tramways, they get their power from stations which burn coal obtained at home and not a foreign product like petrol.

\section{Radio Equipment for Deep Sea Trawlers}

Few realise what a great boon radio equipment is to deep sea trawlers. Some of these small vessels fish at all times of the year on fishing grounds many hundreds of miles away from their home ports. Trawlers from Hull and Grimsby regularly fish off Bear Island near Spitsbergen; others trawl in the Davis Straits, 2400 miles from their base, and some off Iceland and in the White Sea. During the winter, which is the best fishing season, it is nearly always dark, and the gales and the intense cold make the work very hazardous. Catches vary considerably and the markets are sometimes glutted and sometimes short of supplies. It is of the greatest importance that the trawlers of the same company should be in close touch with one another, and this they can do by radio telegraphy. In the Engineering Supplement to Siemens' Magazine for March a discription is given of a radio station for use on board trawlers. The whole of the apparatus is contained in a teak case which can easily be passed through hatchways of normal size. This can be fitted into quite a small cabin or even into a cupboard. It receives and sends messages on wave-lengths between 20 and 20,000 metres, the required electricity being obtained from primary batteries and a small alternator. The output of the alternator does not exceed 300 watts, but the range with coast stations is often of the order of 1000 miles. In addition, Messrs. Siemens have designed a 'direction finder' which is simple to operate. Many trawlers also have a Marconi depth finder so as to enable them to locate the places where the required fish are likely to be found. Recent inventions have made the life of the trawlerman much easier and much more secure.

\section{A High Voltage Electrostatic Generator}

IN the August number of the Scientific American, there is a short account of the new electrostatic generator which is being built by $R$. J. van de Graaff at the Massachusetts Institute of Technology. From this and some notes which have appeared elsewhere, it seems that it is a large-scale elaboration of the Wimshurst type of machine, consuming considerable power in its operation. The dises of the Wimshurst machine are replaced by silk belts, and the separation of charges made regenerative. The charges are collected on enormous metal spheres, sufficiently large to hold an experimenter and apparatus, and capable of being charged to 10-15 million volts without flashover. Details of the power available for such experiments as those of Cockroft and Walton of the Cavendish Laboratory, Cambridge, are not given, but it is to be presumed that calculations have been made on the basis of Gamow's theories of the artificial disintegration of nuclei which justify the undertaking. The return to Faraday's device of sitting within highly charged apparatus is interesting.

\section{Night-Crowing of Cockerels}

A communication by $D$. Sinitsin on the nightcrowing of the cock, published in Russian in 1924, in the Records of the Bielorussian Institute of Agriculture, attracted the attention of the late M. Bigourdan, the veteran French astronomer. Shortly before M. Bigourdan's death, Mr. Sinitsin provided him with full information on the subject. Mr. Sinitsin (1750 Wilton Place, Hollywood, California) has now sent to the Editor a record, illustrated by a diagram, of the fourteen nights' crowings of a cock kept in his study at Minsk, Russia, in 1923. Regular crowings occurred between 11 P.M. and 5 A.M., when they could be measured by hours, each crowing coming within ten minutes of the hour; before 11 P.M. there was no crowing, and after 5 A.M. it was not regular. Changes of atmospheric pressure, music, light, and talking in the room did not affect the regularity. The second and third crowings, especially when at 2 and 4 A.M., were the most vigorous and accompanied by flapping. It is suggested that the paroxysms of crowing are caused by something in the atmosphere perceived by the cock in some unknown fashion, and that it is connected with the rotation of the globe, waves from the sun-lighted side of this spreading to the darkened side. It is also put forward that the twelve-system of timereckoning had its origin from the period when time could only be measured at night by cock-crowing, and that by artificial selection a race of cocks might be produced which would tell the time with clock-like regularity.

\section{Meteorology of the Past, Present, and Future}

Sir NaPIER Shaw (Scientia, June 1932) characterises the meteorology of yesterday by the accumulation of climatological data, their discussion in connexion with the general circulation of the atmosphere, and their analysis by the methods of harmonic analysis and coefficients of correlation. He emphasises the past concentration of attention on depressions and anticyclones, and the doubts which arise in connexion with reduction of pressures to mean sea level. The meteorology of to-day is essentially concerned with the interactions of air currents of different origin at the surface of separation which is known as the "polar front', the methods of discussion being associated with the Norwegian school of meteorologists. The meteorology of to-morrow is, in Sir Napier's opinion, to concern itself with entropy as the specification of the qualification of any mass of air for its position. The name 'weather potential' is suggested as another name for entropy. Sir Napier suggests that all motion in the atmosphere, apart from penetrative convection, is along isentropic surfaces, so that these surfaces act as automatic guides to all moving air, in much the same sense that the banks of a river act as automatic guides to the water in the river. He also suggests, though very briefly, that regions of high and low pres-

No. 3278, VoL. 130] 
sure in the atmosphere are created by currents of air associated with straight isobars, in which the velocity is not of the right amount to produce a balance between pressure gradient and the deviating force due to the earth's rotation, and that the effect of gravitational forces on masses of air, the entropy of which differs from that of their environment, can develop a column of low pressure.

\section{The People's Cinema University}

A IEADING recommendation of the Commission on Educational and Cultural Films which was set up in 1929 was the establishment of a National Film Institute (see Nature for June 18, p. 911). One is interested, therefore to observe the scheme evolved by Sir James Marchant and Sir Oswald Stoll for the establishment in London of the People's Cinema University. The university, it is stated, would consist of a central building, from which lecture halls equipped with sound-film installations for the regular exhibition of films would radiate. In the central dome there would be a Zeiss planetarium. There would also be reading rooms, offices, etc., available for film patrons and societies. All these features are combined in an imposing general design prepared by Sir Giles Gilbert Scott. The films would be made in co-operation with an expert educational board to meet the requirements of teachers and scholars, and would be distributed and collected by motor cinema vans throughout the country. Projectors also would be supplied to schools, churches, and institutions. In his broadcast address and in letters to the Times, Sir James has directed attention to useful educational work already accom. plished. The catalogues issued by Visual Education, Ltd., indeed, list quite an impressive series of educational and cultural films. Sir James believes, therefore, that the time is ripe for such a venture as the People's Cinema University, which, in its own sphere, would attempt work resembling that of the B.B.C.

\section{Change in Colour of Birds due to Exposure}

Mr. P. J. Norman, in Cage Birds for Aug. 6 (p. 70), cites a remarkable case in which a black-headed variety of the budgerigar, after being turned out into an outdoor aviary provided with a 'flight' or net. roofed annexe, so that the birds were exposed to rain if they wished it, has resumed the normal yellow colouring of the head. The breeder of this bird, it seems, has stated that all of its nest-fellows were also black-headed, and that these had retained the black head through a moult. The family had been bred indoors, in a cage, and it is suggested that in the case of the bird which reverted, the exposure to open air and rain in its new quarters had brought about the return to normal plumage. It would, however, be well worth while to see whether outdoor treatment would operate in this way with the rest of the brood; or, if they be still kept indoors, whether they will produce black-headed young. It may be noted here that of the first two specimens of the rare East Asiatic Derbyan parrakeet the London Zoological Society possessed, one became black-headed and afterwards re- verted to normal, while its companion did not change, though both lived in the same cage indoors in the old Parrot House.

\section{Helminthological Abstracts}

ONE of the first fruits of the various agricultural bureaux formed by the Imperial Agricultural Research Conference has been the establishment of a number of abstracting journals, the latest of which to appear being Helminthological Abstracts, under the editorship of Prof. R. T. Leiper. This new journal, which is issued as a supplement to the Journal of Helminthology, differs in several important respects from the others. Papers are arranged by journals, not by subjects, and each abstract is printed so that the first sentence is in effect an extended title ; the remainder is a succinct abstract of the chief results obtained by the authors. The Abstracts will be issued in five parts each year, the first of these being in April. This will enable a single volume to cover the entire literature for the calendar year, so that, in addition to keeping the current literature before the reader, it will when bound form a complete summary of the year's work. It is priced at 16s. 6d. a volume, post paid, and is obtainable from the Institute of Agricultural Parasitology, St. Albans. Another publication from the same Bureau is the "Bibliography of Helminthology" for the year 1930 (6s.). This volume contains references to more than 900 titles in 346 different journals. These titles are arranged by journals, with an adequate authors' index. The volume has the same format as the Abstracts, and although issued separately could be bound with the completed volumes to form an invaluable index to the journals abstracted and the authors of the papers.

\section{Prof. Richard Willstätter}

Die Naturwissenschaften for Aug. 12 is a special issue in honour of Prof. Richard Willstätter's sixtieth birthday. The memoir contains a series of articles by experts upon the fruitful results of his memorable researches in organic chemistry. Prof. F. Haber refers to the successful campaigns which Willstätter has conducted in different branches of biochemistry, for the exceptional skill which he displayed in elucidating chemical structures was principally concentrated upon problems closely related to living matter. Prof. Pummerer reviews the results of forty years of strenuous endeavour. First comes a masterly series of papers upon alkaloids, culminating in the synthesis of tropin and cocaine; then for a while aromatic structures claim attention, particularly quinone-imines, aniline black, and cyclo-octa-tetraene. But Willstätter's interest in plant life led him to the study of the compounds to which plants owe their distinctive colours. Thus chlorophyll, carotene, and the anthocyanins were investigated in turn, and the success attained in each of these branches led him to the further problem of assimilation by plants. This involved the study of enzymes, which has yielded some astonishing results in recent years. Prof. L. Zechmeister describes the main lines of Willstätter's work on carotinoids and the important hydrocarbon carotene, which has come into prominence on account

No. 3278, VoL. 130] 